\title{
Twofold C-H Activation-Based Enantio- and Diastereoselective C- H Arylation Using Diarylacetylenes as Rare Arylating Reagents
}

\author{
Panjie Hu, Lingheng Kong, Fen Wang, ${ }^{*}$ Xiaolin Zhu, Xingwei Li* \\ [a] P. Hu, Dr. L. Kong, Dr. F. Wang, Dr. X. Zhu, Prof. Dr. X. Li \\ School of Chemistry and Chemical Engineering \\ Shaanxi Normal University (SNNU) \\ Xi'an 710062 (China) \\ E-mail: lixw@snnu.edu.cn \\ Prof. Dr. X. Li \\ Institute of Molecular Science and Engineering, Institute of Frontier and Interdisciplinary Sciences, Shandong University, Qingdao \\ 266237, China
}

Supporting information for this article is given via a link at the end of the document.

\begin{abstract}
C}-\mathrm{H}$ bond activation has been established as an attractive strategy to access axially chiral biaryls, and the most straightforward method is direct $\mathrm{C}-\mathrm{H}$ arylation of arenes. However, the arylating source has been limited to several classes of reactive and bulky reagents. Reported herein is rhodium-catalyzed 1:2 coupling of diarylphosphinic amides and diarylacetylenes for enantio- and diastereoselective construction of biaryls with both central and axial chirality. This twofold $\mathrm{C}-\mathrm{H}$ activation reaction stays contrast to the previously explored Miura-Satoh type 1:2 coupling of arenes and alkynes in terms of chemoselectivity and proceeded under mild conditions with the alkyne acting as a rare arylating reagent. Both $\mathrm{C}-\mathrm{H}$ activation events are stereo-determining and are under catalyst control, with the $2^{\text {nd }} \mathrm{C}-\mathrm{H}$ activation being diastereo-determining in a remote fashion. Analysis of the stereochemistries of the major and side products suggests moderated enantioselectivity of the initial C-H activationdesymmetrization process. However, the minor stereoisomeric $(R)$ intermediate is consumed more readily in undesired protonolysis, eventually resulting in high enantio- and diastereoselectivity of the major product.
\end{abstract}

\section{Introduction}

Axially chiral compounds represent a large family of aromatics that have found wide applications as medicinally important agents, organocatalysts, and chiral ligands or catalysts. Numerous organocatalytic and metal-catalyzed synthetic methods have been developed to access atropo-enriched biaryls. ${ }^{[1]}$ Despite the progress, there is a general trend to access these synthetic targets by overcoming some drawbacks such as use of stoichiometric chiral auxiliaries and the requirement of prefunctionalized starting materials. In this regard, asymmetric C-H bond activation ${ }^{[2]}$ has been established as an atom- and step-economic approach to address these limitations, allowing generation of molecular complexity in a single step starting from readily available reagents.

The effectiveness of C-H bond activation-based generation of axially chirality has been witnessed by the increasing number of reports in the past decade. Early work focused on palladium-catalyzed C-H activation, ${ }^{[3]}$ and the majority of recent studies takes advantage of size-increasing effect via dynamic kinetic transformation of arenes that already bear an axis. ${ }^{[4]}$ Our group also realized biaryl synthesis by alternative dynamic kinetic transformation of the coupling reagent (alkynes). ${ }^{[5]}$ Direct arylation of arenes with concurrent generation of an axis seems a more straightforward protocol. In 2012 Yamaguchi and Itami applied naphthyl boronic acids as an arylating reagent in Pd-catalyzed arylation of thiophenes. ${ }^{[6]}$ In 
2020, Cramer applied 1-naphthyl bromide as the arylating reagent for biaryl synthesis. ${ }^{[7]}$ Great progress has been made in Rh- or Ir-catalyzed C-H activation. ${ }^{[8]}$ In 2017 , Waldmann ${ }^{[9]}$ realized asymmetric C-H arylation of sterically hindered benzamides with diazonaphthoquinones catalyzed by a chiral $\mathrm{Rh}$ (III) cyclopentadienyl (Scheme 1a). Cramer elegantly realized desymmetrization-arylation of phosphine oxides using a chiral $\mathrm{Cp}^{\mathrm{X}} \mathrm{Ir}(\mathrm{III})$ catalyst in combination with a chiral acid. ${ }^{[10]}$ Werecently applied $o$ alkynylaniline as an arylating reagent for 2,3'-biindolyl synthesis. ${ }^{[11]}$ In 2020, You ${ }^{[12]}$ achieved arylation of arenes via dynamic kinetic transformation of arenes using heteroarenes as an arylating reagent.

a) Enantioselective Synthesis of Axially Chiral Naphthalenes

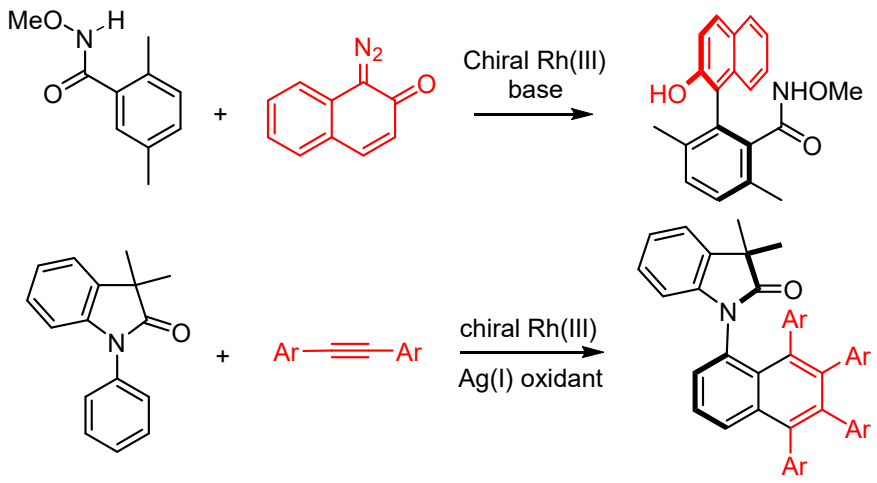

b) Atroposelective Biaryl Synthesis via Two Classes of 1:2 Coupling with Alkynes
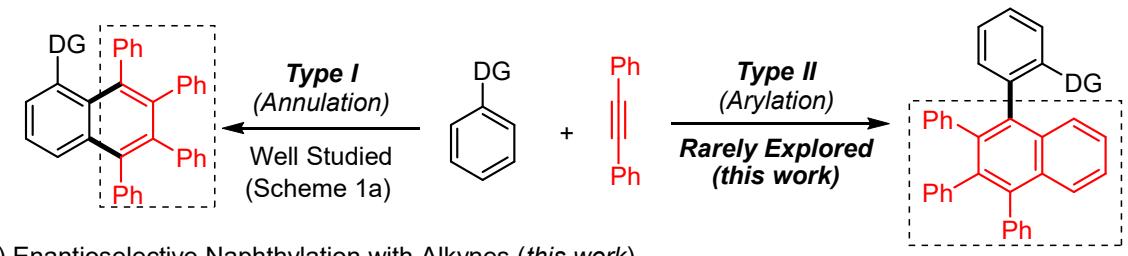

c) Enantioselective Naphthylation with Alkynes (this work)
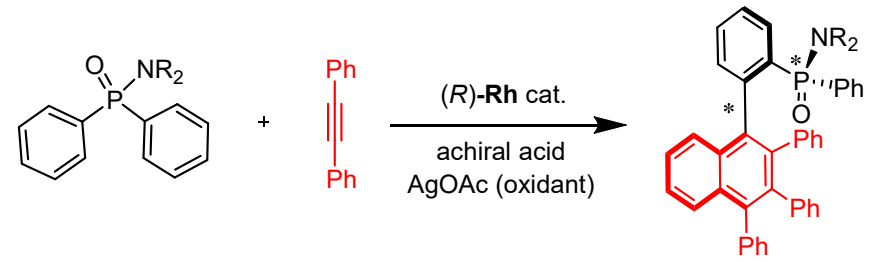

- Twofold C-H Activation

- Rare Type-II Naphthylation

- Excellent Diastereoselectivity

- High Enantioselectivity

- Product Applications

Scheme 1 Axially Chiral Biaryls via C-H Arylation of Arenes

Despite the progress, generation of axial chirality calls for employment of more readily available arylating reagents. Since 1-naphthyl groups represent a typical bulky aryl ring, formation of 1-naphthyls offers a convenient approach to biaryl synthesis. In this context, Wang ${ }^{[13]}$ reported in 2019 Satoh-Miura type $^{[14]} 1: 2$ annulation between amides and alkynes for atroposelective synthesis of naphthalenes (Scheme 1a), where the alkyne contributes four carbon atoms to the naththalene ring (Type I coupling), and the axis preexists in the arene substrate, which amounts to dinamic kinetic transformation of the arene substrate. On the other hand, alternative role of alkynes may be invoked in a different chemoselectivity (Scheme 1b, Type II reaction) where the chiral axis is newly constructed. While this reaction also proceeds via twofold $\mathrm{C}-\mathrm{H}$ activation and 1:2 coupling, ${ }^{[15]}$ the alkyne contributes ten carbon atoms during the naphthalene ring formation, and one of arene ring in the alkyne unit undergoes $\mathrm{C}-\mathrm{H}$ activation. This unusual selectivity has been disclosed in two reports. ${ }^{[16]}$ However, no atroposelective system has been developed. We now report enantio- and diastereoselective $\mathrm{C}-\mathrm{H}$ activation-desymmetrization of phosphinamide (Scheme 1c), leading to synthesis of biaryls with axial and P-central chirality, in which both the $\mathrm{C}-\mathrm{H}$ activation events are stereo-determining. 


\section{Results and Discussion}

We embarked on our studies by screening a series of arenes bearing different directing groups using the Cramer-type $(R)$-Rh1 catalyst. ${ }^{[17]}$ While some arenes were found to undergo the Satoh-Miura type annulation with diphenylacetylene, the desired chemoselectivity was consistently realized when arenes bearing a $\mathrm{P}=\mathrm{O}^{[11,18]}$ directing group were used under oxidative conditions (AgOAc, DCM, Table 1). It was discovered that phosphinamides with dialkylamino groups underwent 1:2 coupling with diphenylacetylene in variable enantioselectivity (77:23 to 97:3 er), and the highest enantioselectivity was observed for a $\mathrm{N}^{i} \mathrm{Pr}_{2}$ substituent. In contrast, $\mathrm{Ph}_{2} \mathrm{P}(\mathrm{O})^{\mathrm{t}} \mathrm{Bu}$ only coupled with lower efficiency and moderate enantioselectivity. Therefore, this substrate (1a) was retained for further optimization.

Table 1. Initial Optimization of the Directing Group. ${ }^{[a]}$
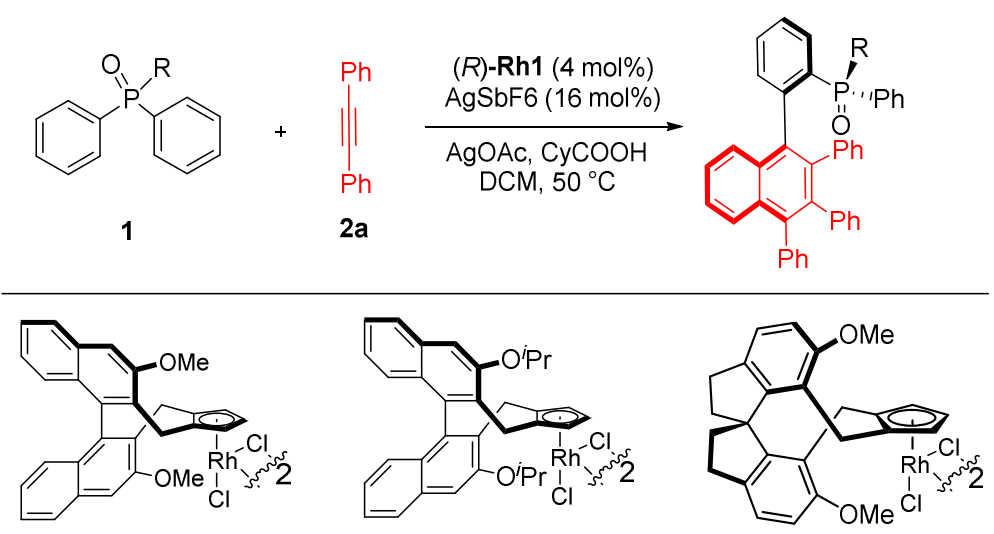

$(R)-\mathrm{Rh1}$

$(R)-\mathrm{Rh} 2$

(S)-Rh3

\begin{tabular}{cccccc}
\hline $\mathrm{R}$ & $\mathrm{NEt}_{2}$ & $\mathrm{NPh}_{2}$ & $\mathrm{NBn}_{2}$ & $\mathrm{~N}\left(\mathrm{CH}_{2}\right)_{4}$ & $\mathrm{~N}\left(\mathrm{CH}_{2}\right)_{5}$ \\
\hline $\begin{array}{c}\text { Yield }(\%)^{b} \\
\text { e.r. }\end{array}$ & 36 & 36 & 41 & 23 & 31 \\
\hline $\mathrm{R}$ & $88: 12$ & $77: 23$ & $88: 12$ & $92: 8$ & $93: 7$ \\
\hline $\mathrm{N}^{\prime} \mathrm{Bu}_{2}$ & $\mathrm{~N}^{\prime} \mathrm{Pr}_{2}$ & $\mathrm{NH}{ }^{t} \mathrm{Bu}$ & $\mathrm{Cy}$ & ${ }^{t} \mathrm{Bu}$ \\
\hline Yield $(\%)^{b}$ & 28 & 53 & 33 & - & 38 \\
e.r. & $94: 6$ & $97: 3$ & $89: 11$ & - & $81: 19$ \\
\hline
\end{tabular}

[a] Reaction conditions: 1 (0.05 mmol), 2a (0.15 mmol), (R)-Rh1 (4 mol\%), AgOTf (16 mol\%), AgOAc (0.15 mmol), CyCO ${ }_{2} \mathrm{H}(0.1 \mathrm{mmol}), \mathrm{DCM}$ $(1 \mathrm{~mL}), 24 \mathrm{~h}, 50^{\circ} \mathrm{C}$. The e.r. was determined by HPLC using a chiral stationary phase. [b] The yield was determined by ${ }^{1 \mathrm{H}} \mathrm{NMR}$ analysis.

The coupling of 1a and diphenylacetylene (2a) was further screened (Table 2 and Supporting Information). Increasing the temperature to $60{ }^{\circ} \mathrm{C}$ improved the reaction efficiency, while no improvement was made when other silver carboxylate oxidants were used (entries 1-3). $\mathrm{CyCO}_{2} \mathrm{H}$ seemed to be a superior acid additive and other common carboxylic acids gave less satisfactory outcomes (entries 4-7). Solvent screening indicated that DCM outperformed other halogenated solvents. AgOTf and $\mathrm{AgSbF}_{6}$ proved nearly equally effective in activating the Rh(III) catalyst (entries 9-10 and Equation 1). While the reaction may afford the undesired hydroarylation product, the enantio- and diastereoselectivities were generally high. In contrast to the Rh1 catalyst, $\mathbf{R h} \mathbf{2}$ and $\mathbf{R h} \mathbf{3}$ gave lower efficiency or enantioselectivity. In all cases, no Type I coupling product was detected. The absolute configuration of (S, S)-3 has been determined by X-ray crystallography (CCDC 2006608). ${ }^{[19]}$

Table 2. Optimization of the Reaction Conditions. ${ }^{[a]}$ 

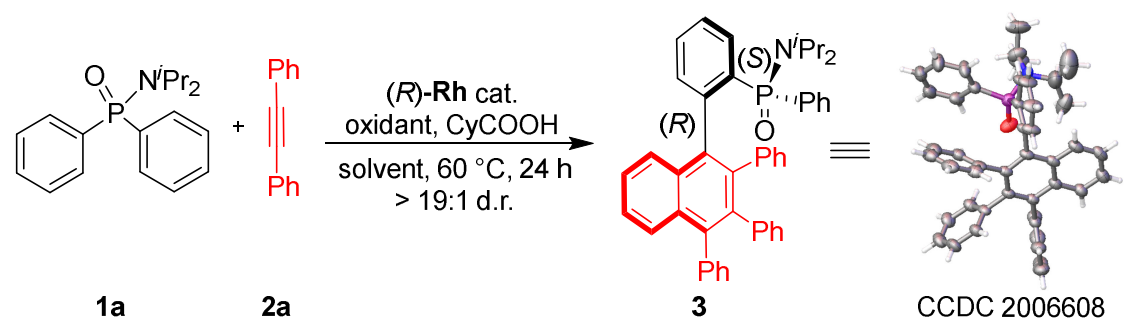

CCDC 2006608

\begin{tabular}{|c|c|c|c|c|c|}
\hline Entry & Ag additive & Oxidant (equiv) & Solvent & Yield [\%] & e.r. \\
\hline 1 & AgOTf & $\mathrm{AgOAc}(3.0)$ & $\mathrm{DCM}$ & 65 & $97: 3$ \\
\hline 2 & AgOTf & ${ }^{i} \mathrm{PrCO}_{2} \mathrm{Ag}(3.0)$ & DCM & 30 & $96: 4$ \\
\hline 3 & AgOTf & $\mathrm{CyCO}_{2} \mathrm{Ag}(3.0)$ & DCM & 56 & $97: 3$ \\
\hline $4^{b}$ & AgOTf & $\mathrm{AgOAc}(3.0)$ & DCM & 57 & $95: 5$ \\
\hline $5^{c}$ & AgOTf & $\operatorname{AgOAc}(3.0)$ & $\mathrm{DCM}$ & 23 & $94: 6$ \\
\hline $6^{d}$ & AgOTf & $\operatorname{AgOAc}(3.0)$ & DCM & 43 & $87: 13$ \\
\hline $7^{e}$ & AgOTf & $\operatorname{AgOAc}(3.0)$ & DCM & 47 & $93: 7$ \\
\hline 8 & AgOTf & $\mathrm{AgOAc}(3.0)$ & DCE & 12 & $98: 2$ \\
\hline 9 & AgOTf & $\operatorname{AgOAc}(3.0)$ & $\mathrm{PhCl}$ & 25 & $97: 3$ \\
\hline 10 & AgOTf & AgOAc (2.5) & DCM & 71 & 98:2 \\
\hline 11 & $\mathrm{AgSbF}_{6}$ & $\mathrm{AgOAc}(2.5)$ & $\mathrm{DCM}$ & 67 & $97: 3$ \\
\hline 12 & $\mathrm{AgPF}_{6}$ & $\mathrm{AgOAc}(2.5)$ & DCM & 30 & $95: 5$ \\
\hline 13 & $\mathrm{AgBF}_{4}$ & $\operatorname{AgOAc}(2.5)$ & DCM & 54 & $96: 4$ \\
\hline $14^{f}$ & AgOTf & $\operatorname{AgOAc}(2.5)$ & DCM & 52 & $97: 3$ \\
\hline $15^{g}$ & AgOTf & $\mathrm{AgOAc}(2.5)$ & DCM & 43 & $90: 10$ \\
\hline
\end{tabular}

[a]Reaction conditions: 1a (0.05 mmol), 2a (0.125 mmol), (R)-Rh1 (4 mol\%), AgOTf (16 mol\%), AgOAc (0.125 mmol) and CyCO ${ }_{2} \mathrm{H}(0.1 \mathrm{mmol})$ in DCM (1 mL), $24 \mathrm{~h}, 60^{\circ} \mathrm{C}$, isolated yield. $>19: 1 \mathrm{dr}$ in all cases. The e.r. was determined by HPLC using a chiral stationary phase. [b]'PrCO ${ }_{2} \mathrm{H}$ $(0.1 \mathrm{mmol})$ instead of $\mathrm{CyCO}_{2} \mathrm{H}$. [c] $\mathrm{PhCO}_{2} \mathrm{H}(0.1 \mathrm{mmol})$ instead of $\mathrm{CyCO}_{2} \mathrm{H}$. [d] ${ }^{t} \mathrm{AmCO}_{2} \mathrm{H}(0.1 \mathrm{mmol})$ instead of $\mathrm{CyCO}{ }_{2} \mathrm{H}$. [e]AcOH $(0.1 \mathrm{mmol})$ instead of $\mathrm{CyCO}_{2} \mathrm{H}$. [f](R)-Rh2 (4 mol\%). [g](S)-Rh3 (4 mol\%).

Having established the optimal reaction conditions, we next examined the scope of the arene substrates (Scheme 2). Symmetric diarylphosphinic amides bearing an electron-donating ( $\mathrm{Me}, \mathrm{Et},{ }^{\mathrm{t}} \mathrm{Bu}$, $\mathrm{OEt}$, and $\mathrm{OMe}$ ), -withdrawing ( $\mathrm{Ph}$ and $\mathrm{CF}_{3}$ ), and halogen groups at the para position of the benzene ring were generally well tolerated, and the corresponding products (4-13) were isolated in moderate to good yields and in 93.5:6.5 to 97.5:2.5 e.r. Arenes bearing meta alkyl and alkoxyl groups were also compatible (14-17), and the $\mathrm{C}-\mathrm{H}$ activation took place at the less hindered ortho $\mathrm{C}-\mathrm{H}$ site in excellent enantioselectivity (95.5:4.5 to 97:3 e.r.). The reaction seemed sensitive to steric effect; introduction of an ortho Me group inhibited the reaction. Other $N, N$-dialkylphosphinamides reacted with slightly lower enantioselectivity (18-21). Similarly, tertiary alkyl amine-derived phosphinamides also reacted with attenuated enantioselectivity (22 and 23). This coupling reaction can be performed in $0.1 \mathrm{mmol}$ scale and was readily scaled to $1 \mathrm{mmol}$ scale. All the products obtained in this work are atropomerically stable and no decrease of enantiopurity and diastereopurity was observed when they were heated in $100{ }^{\circ} \mathrm{C}$. In most cases, competitive 1:1 C-H olefination side products were observed, which accounts for the moderate isolated yields of the major 1:2 coupling products in most reactions. These olefination sideproduct were obtained in much lower enantioselectivity. Significantly and surprisingly, the absolute configuration of a representative $\mathrm{C}-\mathrm{H}$ olefination product $\left(\mathbf{3}^{\prime}\right)$ has also been determined to be $(R)$ configured (CCDC2085200), which stands in sharp contrast to the $(S)$ - P central chirality in the final 
product. These observations may offer insight into the mechanism of this coupling system.
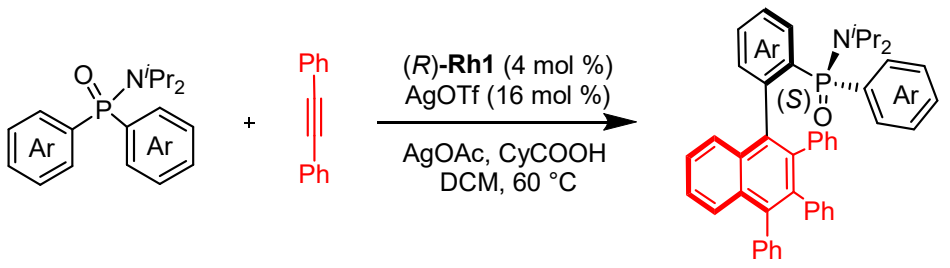

$2 a$

3-23

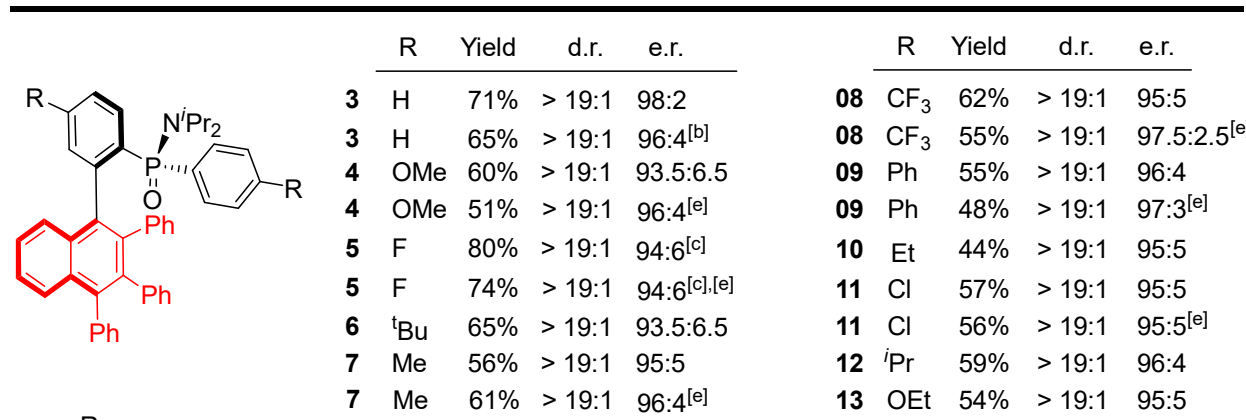

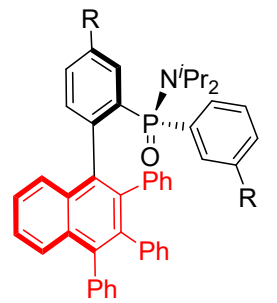

\begin{tabular}{rlrrll} 
& \multicolumn{1}{r}{$\mathrm{R}$} & Yield & d.r. & e.r. \\
\cline { 2 - 5 } 14 & $\mathrm{Me}$ & $57 \%$ & $>19: 1$ & $96: 4$ \\
14 & $\mathrm{Me}$ & $62 \%$ & $>19: 1$ & $96.5: 3.5^{[\mathrm{e}]}$ \\
15 & $\mathrm{Cl}$ & $38 \%$ & $>19: 1$ & $95: 5$ \\
16 & OMe & $40 \%$ & $>19: 1$ & $97: 3$ \\
17 & Et & $51 \%$ & $>19: 1$ & $95.5: 4.5$
\end{tabular}

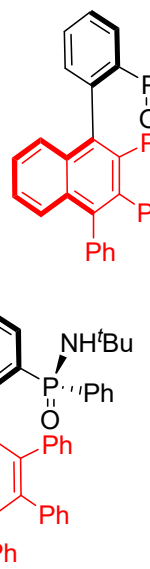

22, 53\%, d.r. $>19: 1,90: 10$ e.r.

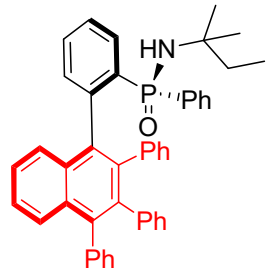

23, $54 \%$, d.r. $>19: 1,93: 7$ e.r. d.r. > 19:1, 91.5:8.5 e.r. Representative
Hydroarylation Product<smiles>[R]c1ccc(P(=O)(N=P)c2ccc([R])cc2/C(=C/Pc2ccccc2)P([R])c2ccccc2)cc1</smiles>
3' $(\mathrm{R}=\mathrm{H}), \quad 13 \%$, 68:32 e.r. 4' ( $R=$ OMe), $17 \%, 70: 30$ e.r. 5' $(R=F), \quad 10 \%, 81: 19$ e.r. 9' $(\mathrm{R}=\mathrm{Ph}), \quad 13 \%, \quad 60: 40$ e.r.

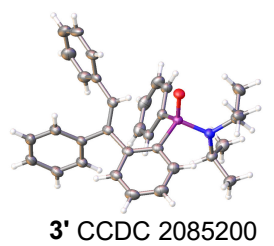

Scheme 2. Scope of Phosphoric Amides in Enantioselective Arylation. [a] Reaction conditions: $\mathbf{1}(0.05 \mathrm{mmol}), \mathbf{2 a}(0.125 \mathrm{mmol}),(R)$-Rh1 (4 mol\%), AgOTf (16 mol\%), AgOAc (0.125 mmol), $\mathrm{CyCO}_{2} \mathrm{H}(0.1 \mathrm{mmol}), \mathrm{DCM}(1 \mathrm{~mL}), 60{ }^{\circ} \mathrm{C}, 24 \mathrm{~h}$. [b] $1 \mathrm{mmol} \mathrm{scale}$. [c] AgSbF $(16 \mathrm{~mol} \%)$. [d] $\mathrm{AgPF}_{6}$ (16 mol\%), $40^{\circ} \mathrm{C}$. [e] $0.1 \mathrm{cmmol}$ scale.

The scope of the diarylacetylene was next explored (Scheme 3). Since the alkyne underwent twofold insertion together with $\mathrm{C}-\mathrm{H}$ activation in one of the arene ring, it is expected that the electronic and steric effects of the alkyne are superposed to give a pronounced effect. Indeed, essentially no desired reaction was detected when di(o-tolyl)acetylene was used. Nevertheless, coupling using various diarylacetylene bearing electron-donating (alkyl and $\mathrm{OMe}$ ) and -withdrawing (halogen, $\mathrm{OCF}_{3}$, and $\mathrm{CF}_{3}$ ) at the para position generally afforded the desired product in moderate yield and good to excellent enantioselectivity (24-33, 91.5:8.5 to 97:3 er). In contrast, the reaction of di-( $m$-tolyl)acetylene and 1a only gave complicated product mixtures. 

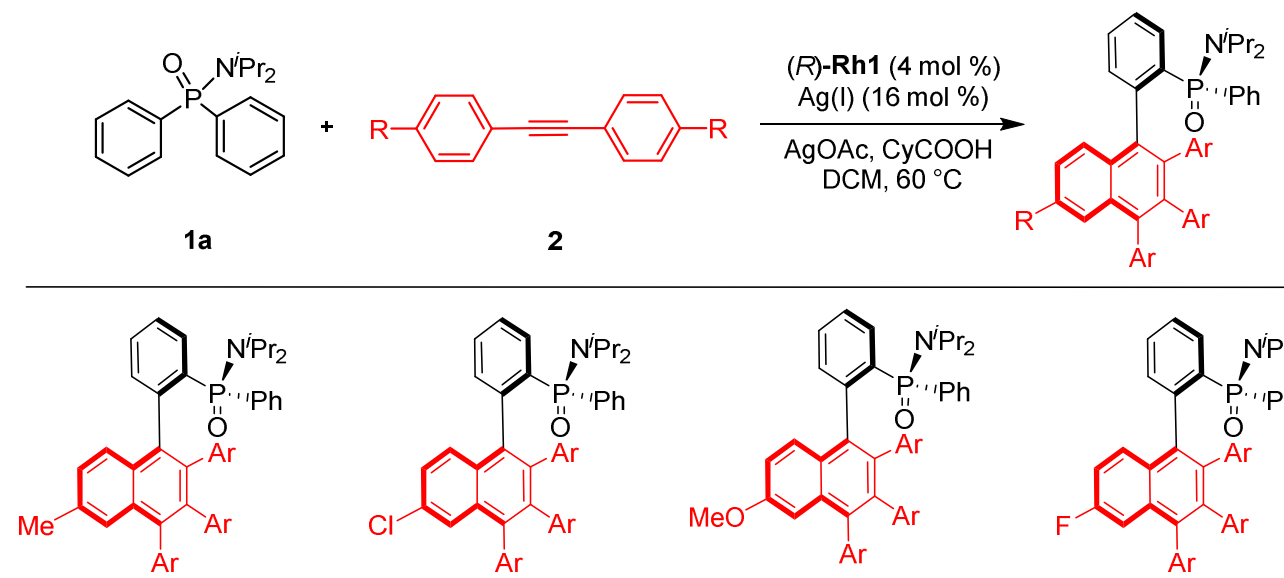

24, $\mathrm{Ar}=4-\mathrm{MeC}_{6} \mathrm{H}_{4}$ $61 \%$, d.r. $>19: 1,95: 5$ e.r. ${ }^{[b]}$ $50 \%$, d.r. $>19: 1,96: 4$ e.r. ${ }^{[b],[e] ~} 42 \%$, d.r. $>19: 1,97: 3$ e.r.

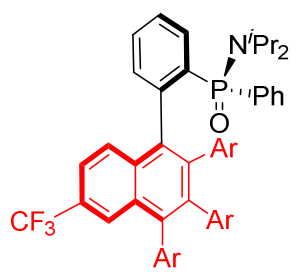

28, $\mathrm{Ar}=4-\mathrm{CF}_{3} \mathrm{C}_{6} \mathrm{H}_{4}, 41 \%$ d.r. $>19: 1,97: 3$ e.r. $^{[c]}$

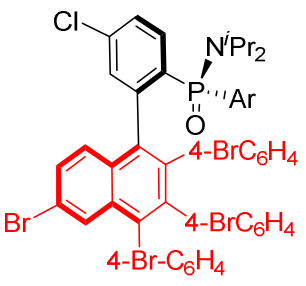

32

$\mathrm{Ar}=4-\mathrm{ClC}_{6} \mathrm{H}_{4}, 41 \%$

d.r. $>19: 1,91.5: 8.5$ e.r. $21 \%$, r.r. $=1: 1^{[d]}, 95: 5$ e.r. $(96: 4$ e.r.)

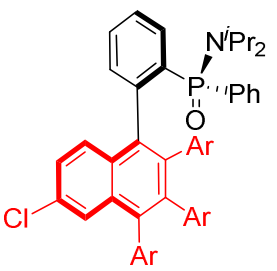

25, $\mathrm{Ar}=4-\mathrm{ClC}_{6} \mathrm{H}_{4}$

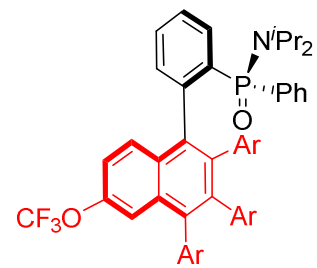

29, $\mathrm{Ar}=4-\mathrm{OCF}_{3} \mathrm{C}_{6} \mathrm{H}_{4}, 45 \%$ d.r. > 19:1, 97:3 e.r.

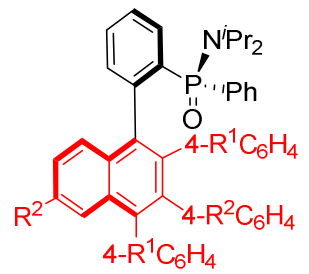

$\mathrm{R}^{1}, \mathrm{R}^{2}=\mathrm{CF}_{3}$ or $\mathrm{MeO}$

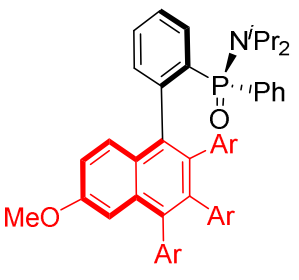

26, $\mathrm{Ar}=4-\mathrm{OMeC}_{6} \mathrm{H}_{4}$ $51 \%$, d.r. $>19: 1,92: 8$ e.r. $^{[b]}$

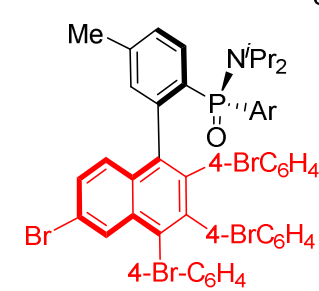
30, $\mathrm{Ar}=4-\mathrm{MeC}_{6} \mathrm{H}_{4}, 47 \%$
d.r. $>19: 1,97: 3$ e.r.

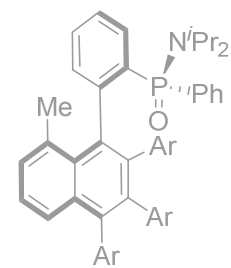

$\mathrm{Ar}=\mathrm{o}-\mathrm{Tol}$ n.r.

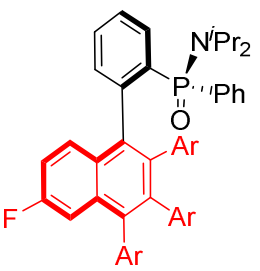

27, $\mathrm{Ar}=4-\mathrm{FC}_{6} \mathrm{H}_{4}$ $57 \%$, d.r. $>19: 1,96.5: 3.5$ e.r. $51 \%$, d.r. $>19: 1,96: 4$ e.r. $^{[\mathrm{e}]}$<smiles>O=P(c1ccccc1)(c1ccccc1)c1c(Br)c(Br)c(Br)c2cc(Br)ccc12</smiles>

31, $\mathrm{Ar}=4-\mathrm{BrC}_{6} \mathrm{H}_{4}$ $46 \%$, d.r. $>19: 1,97: 3$ e.r. $40 \%$, d.r. $>19: 1,97: 3$ e.r. $^{[\mathrm{e}]}$

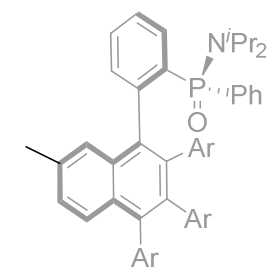

$\mathrm{Ar}=m$-Tol messy reaction

Scheme 3. Scope of Diarylacetylene in Enantioselective Arylation. [a] Reaction conditions: 1a (0.05 mmol), 2 (0.125 mmol), (R)-Rh1 (4 mol\%), $\operatorname{AgOTf}(16 \mathrm{~mol} \%), \operatorname{AgOAc}(0.125 \mathrm{mmol})$, and $\mathrm{CyCO}_{2} \mathrm{H}(0.1 \mathrm{mmol})$ in $\mathrm{DCM}(1 \mathrm{~mL})$ at $60{ }^{\circ} \mathrm{C}, 24 \mathrm{~h}$. [b] $\mathrm{CHCl}_{3}$. [c] $(R)-\mathrm{Rh} 2(4 \mathrm{~mol} \%)$ was used. [d] r.r. was determined by HPLC. [e] $0.1 \mathrm{mmol}$ scale.

Synthetic applications of product $\mathbf{3}$ was demonstrated in $1 \mathrm{mmol}$ scale (Scheme 4). Treatment of $\mathbf{3}$ with MeOTf followed by LAH reduction afforded diarylphosphine oxide $\mathbf{3 4}$ in moderate yield and low diastereoselectivity, and each diastereomer was obtained in 95:5 e.r. Pd-catalyzed phenylation of the diastereomeric mixture of $\mathbf{3 4}$ gave the corresponding triarylphosphine oxide. Standard reduction by $\mathrm{SiHCl}_{3}$ provided the axially chiral phosphine $\mathbf{3 5}$ in high yield and in 95:5 e.r. Phosphine $\mathbf{3 5}$ has been applied as a chiral ligand in palladium-catalyzed asymmetric allylic alkylation of an allyl acetate, affording product 36 in 95:5 er. 


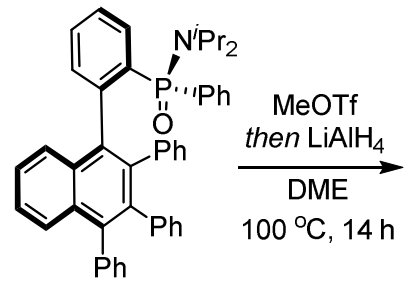

3 ( $98: 2$ e.r.)

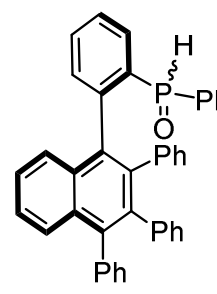

34, 54\%, 1.6:1 d.r. 95:5 e.r. (95:5 e.r.)
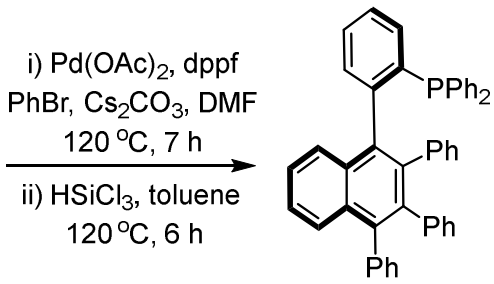

$35,88 \%, 95: 5$ e.r. after recrystallization $97: 3$ e.r.<smiles>CCOC(=O)CC(=O)OCC</smiles>

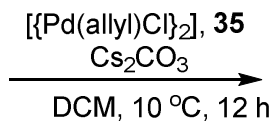<smiles>CCOC(=O)C(C(=O)OCC)C(/C=C/c1ccccc1)c1ccccc1</smiles>

$36,81 \%, 95: 5$ e.r.

Scheme 4. Product Transformations and Applications.

Photophysical properties of selected products $(\mathbf{3}, \mathbf{4}, \mathbf{7}, \mathbf{9}$, and 31) were next examined (Figure 1). These compounds typically exhibited three absorption bands in the UV-Vis spectroscopy, ranging from 225 to $317 \mathrm{~nm}$. Fuorescence emission was observed (exicted at $300 \mathrm{~nm}$ ), and the absolute quantum yield was determined. The highest quantum yield of 0.5 was found for product 3 (Table 2). These data may indicate the potentiality of our products as organic semiconductors.
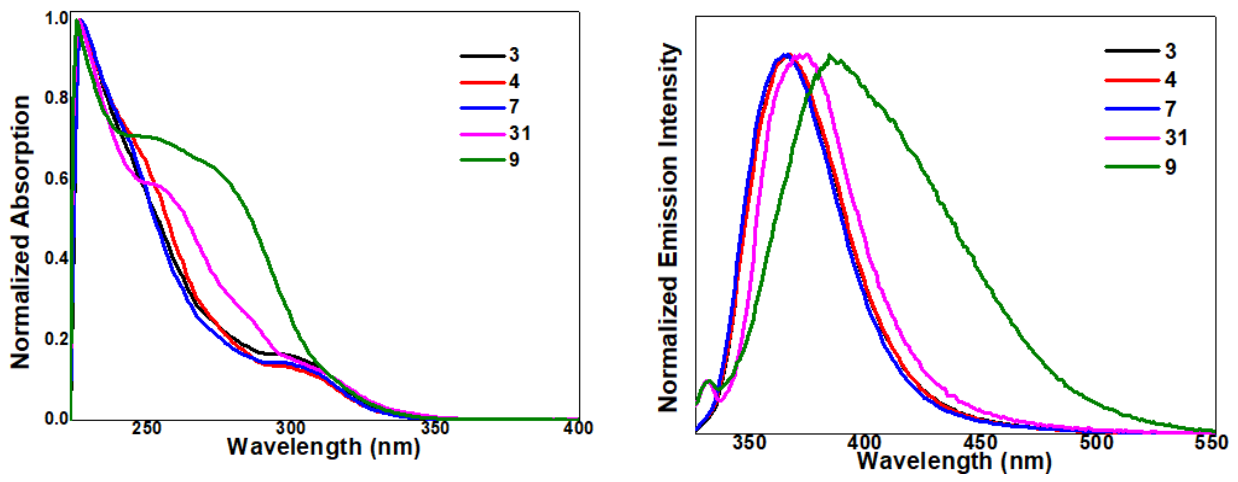

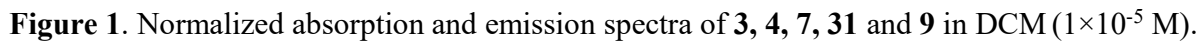

Table 2: Photophysical properties of selected products in $\mathrm{CH}_{2} \mathrm{Cl}_{2}\left(1 \times 10^{-5} \mathrm{M}\right)$

\begin{tabular}{cccc}
\hline Compound & $\lambda_{\text {abs }}{ }^{[\mathrm{al}]}[\mathrm{nm}]$ & $\lambda_{\text {em }}{ }^{[\mathrm{b}]}[\mathrm{nm}]$ & $\phi_{F}{ }^{[\mathrm{cc}]}$ \\
\hline $\mathbf{3}$ & $227,297(\mathrm{sh}), 317(\mathrm{sh})$ & 366 & 0.50 \\
$\mathbf{4}$ & $227,245(\mathrm{sh}), 297(\mathrm{sh})$ & 366 & 0.48 \\
$\mathbf{7}$ & $227,297(\mathrm{sh}), 317(\mathrm{sh})$ & 363 & 0.47 \\
$\mathbf{3 1}$ & $225,254(\mathrm{sh}), 303(\mathrm{sh})$ & 372 & 0.003 \\
$\mathbf{9}$ & $225,251(\mathrm{sh}), 273(\mathrm{sh}), 316(\mathrm{sh})$ & 384 & 0.005 \\
\hline
\end{tabular}

We next briefly explored the mechanism of this naphthylation reaction. H/D exchange between phosphinamide 1a and $\mathrm{CD}_{3} \mathrm{CO}_{2} \mathrm{D}$ under the standard conditions gave appreciable $\mathrm{H} / \mathrm{D}$ exchange at the ortho positions (Scheme 5a). However, only slight exchange was observed when diphenylacetylene was present, indicating that the $\mathrm{C}-\mathrm{H}$ activation was largely irreversible in the catalytic system. Two KIE experiments were next conducted. The parallel reactions using $1 \mathrm{a}$ and $\mathbf{1 a}-d_{10}$ gave $k_{\mathrm{H}} / k_{\mathrm{D}}=3.5$ (Scheme $5 b$ ), suggesting that the $1^{\text {st }} \mathrm{C}-\mathrm{H}$ activation is turnover-limiting. In contrast, $\mathrm{C}-\mathrm{H}$ activation of the alkyne is likely rapid ( $\mathrm{KIE}=1.2$, Scheme $5 \mathrm{c}$ ). This conclusion seems reasonable because the $2^{\text {nd }} \mathrm{C}-\mathrm{H}$ activation leads to a thermodynamically stable rhodacycle (vide infra) and is probably also kinetically feasible. In 
additon, the kinetic isotope effect with respect to the formation of the 1:1 C-H olefination side product was also determiend by parallel reactions, and a consistently large value was obtained, indicating no change of the turnover-limiting step.

(a)<smiles>O=[PH](=O)([18OH])c1ccccc1</smiles>

(b)

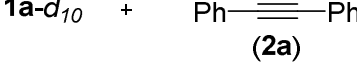

(c)

$$
\begin{aligned}
& 1 \mathrm{a}+\mathrm{Ph} \frac{\overline{\overline{(2 a)}}}{\mathrm{Ph}} \\
& 1 \mathrm{a}+\mathrm{C}_{6} \mathrm{D}_{5} \equiv \mathrm{C}_{6} \mathrm{D}_{5}
\end{aligned}
$$$$
1 \mathrm{a}+\mathrm{Ph} \frac{\overline{\overline{(2 a)}}}{\overline{\left(2 a-D_{10}\right.}} \mathrm{Ph}
$$

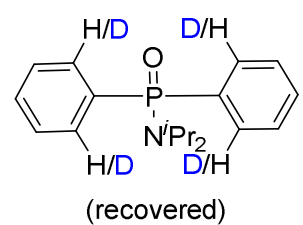

$36 \%$ D without $2 a$

$5 \% \mathrm{D}$ with $2 \mathrm{a}$

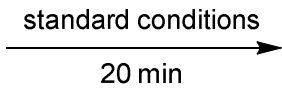

standard conditions

$20 \mathrm{~min}$

$\stackrel{\text { standard conditions }}{\longrightarrow}$

$20 \mathrm{~min}$

standard conditions

$20 \mathrm{~min}$

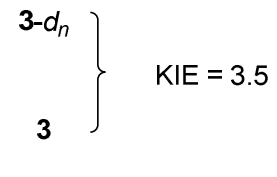

$\left.\begin{array}{c}3-d_{n} \\ 3\end{array}\right\} \quad \mathrm{KIE}=1.2$

Scheme 5. Mechanistic Studies.

A plausible mechanism of the coupling of $\mathbf{1 a}$ and $\mathbf{2 a}$ is proposed (Scheme 6). The $1^{\text {st }} \mathrm{C}-\mathrm{H}$ activation likely occurs via carboxylate-assisted concerted metalation-deprotonation (CMD) to give rhodacyclic intermediate $\mathbf{B}$, which is enantio-determining with respect to the P-stereogenic center. The insertion of the $1^{\text {st }}$ diphenylacetylene gives a rhodacycle C. Subsequent cis-trans isomerization of the $\mathrm{Rh}$ (III) alkenyl moiety in $\mathbf{C}$ is proposed to give $\mathrm{Rh}$ (III) vinyl $\mathbf{D}$. The $2^{\text {nd }}$ ortho $\mathrm{C}-\mathrm{H}$ activation then occurs to give a stable rhodacyclic ${ }^{[14]}$ intermediate E. The Satoh-Miura coupling selectivity was not observed due to more facile cis-trans isomerization in our case, which is probably driven by formation of thermodynamically stable intermediate $\mathbf{E}$. A related signal of $\mathrm{m} / \mathrm{e}=984.3068$ was indeed observed in mass spectrometric analysis of a reaction mixture. This $2^{\text {nd }} \mathrm{C}-\mathrm{H}$ activation is diastereo-determining, and the axial chirality is retained in the $2^{\text {nd }}$ alkyne insertion and $\mathrm{C}-\mathrm{C}$ reductive elimination of $\mathbf{F}$ or $\mathbf{F}$ '.

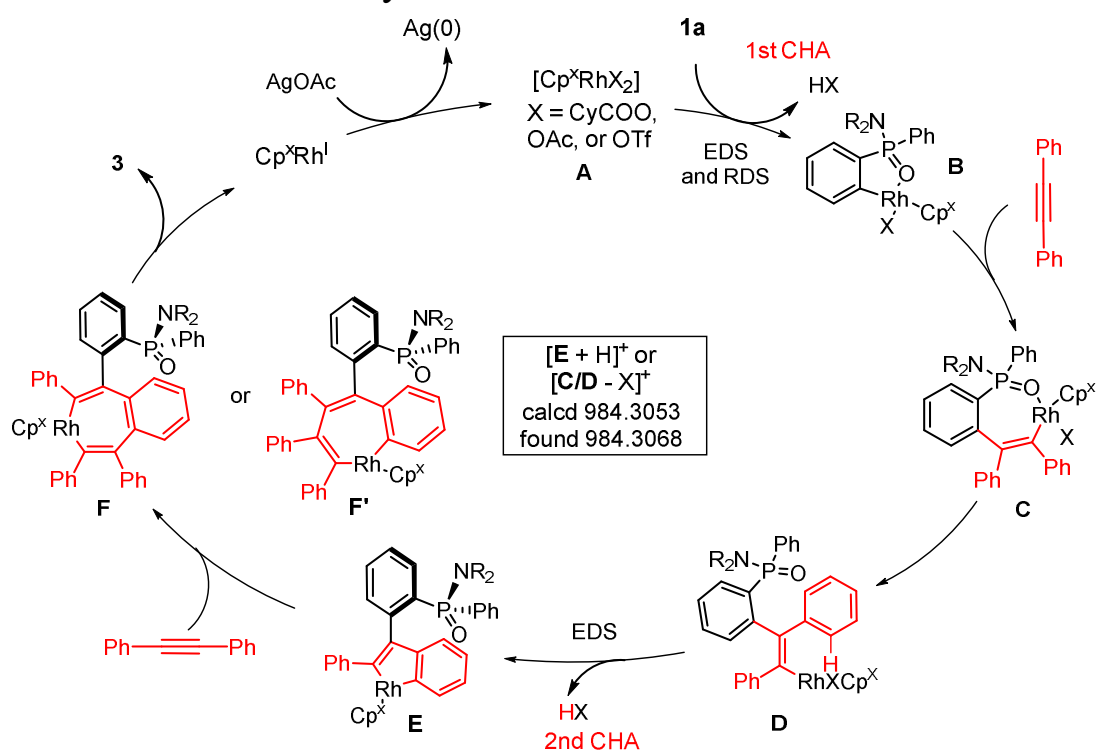

Scheme 6. Proposed Catalytic Cycle (EDS = enantiodetermining step, DDS = diastereodetermining step, RDS = rate-determining step). 


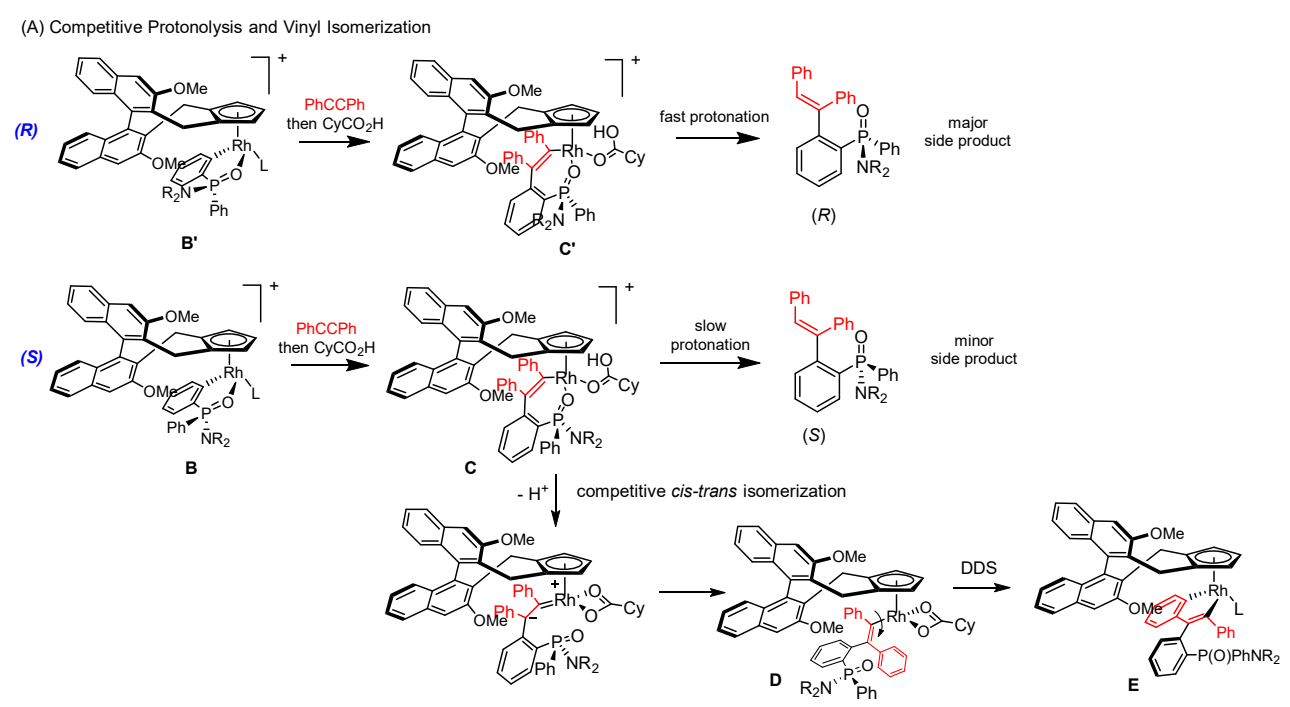

(B) Entiopurity of the Side Product versus the Acid Amount

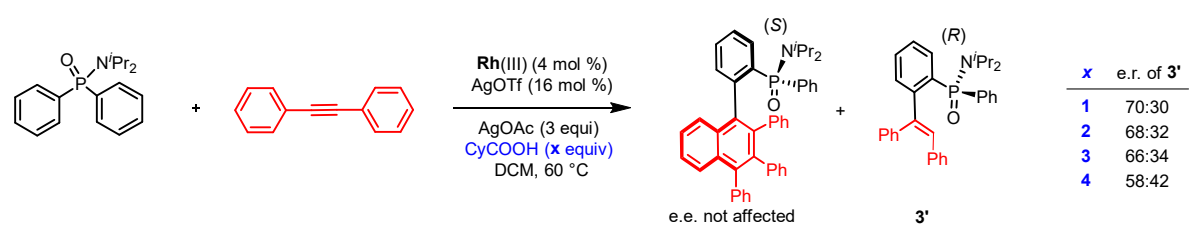

Scheme 7. Rationalization of the Stereochemistries of the major and side products.

The observed olefination side product was taken onto account of rationalization of the observed major and side products (Scheme 7A). The $\mathrm{C}-\mathrm{H}$ activation of the diphenylphosphinic amide is enantiodetermining and it slightly favors formation of the $(S)$ configured P-chiral intermediate (B). Following the parallel alkyne insertion, both intermediates $(S)-\mathbf{C}$ and $(R)-\mathbf{C}^{\prime}$ are generated. Clearly, two subsequent competing processes are existing: these two $\mathrm{Rh}(\mathrm{III})$ vinyl species may undergo protonolysis versus the desired cis-trans isomerization of the vinyl group to allow for the $2^{\text {nd }} \mathrm{C}-\mathrm{H}$ activation. On the basis of the observed opposite configurations of the major and the side products, it is possible that although both protonoly $\mathbf{C}$ and $\mathbf{C}^{\prime}$ is competitive, the protonolysis of the $(R)-\mathbf{C}^{\prime}$ intermediate likely carries a slightly lower barrier. This eventually leads to overall moderate enantioselectivity of the $(R)$ - olefination side product $\mathbf{3}^{\mathbf{6}}$. Accordingly, due to the relatively less favored protonolysis of the $(\boldsymbol{S})$-C, it rather prefers to undergo cis-trans isomerization to allow formation of $\mathbf{D}$. In the $2^{\text {nd }} \mathrm{C}-\mathrm{H}$ activation of $\mathbf{D}$, the bulky aminophosphoryl group stays distal to the chiral ligand to minimize steric repulsion during the CMD process. This sets up the axial chirality in intermediate $\mathbf{E}$ and it is retained thereafter. Of note, the enantioselectivity of the $2^{\text {nd }} \mathrm{C}-\mathrm{H}$ activation process is under remote control and is also under catalyst control since this C-H site is distal to the bulky aryl group. This proposal also seems to be consistent with our observations of acid amount-dependent enantiopurity of the olefination product $3^{6}$ (Scheme 7B). There is an obvious trend of decreasing enantiopority of $\mathbf{3}^{\mathbf{6}}$ with increaing of the aicd amount. Since more acid favors protonolysis of $(S)$-C but disfavors the cis-trans isomerization, this trend is expected.

\section{Conclusion}

In summary, we have achieved the 1:2 coupling of phosphinamides with diarylacetylenes for enantioand diastereoselective synthesis of axially chiral biaryls bearing a P-stereogenic center. The reaction proceeded via desymmetrization of phosphinamides, with the alkyne being a rare arylating reagent. Dual activation of $\mathrm{C}-\mathrm{H}$ bonds in the phosphinamide and the diarylacetylene has been invoked, with each being stereo-determining. The reactions feature mild conditions, high enantioselectivity, and excellent 
diastereoselectivity. Analysis of the stereochemistries of the major and side products suggests moderated enantioselectivity of the initial $\mathrm{C}-\mathrm{H}$ activation-desymmetrization process. However, the minor stereoisomeric $(R)$ intermediate is consumed more readily in undesired protonolysis, resulting in high enantioselectivity of the major product (with Horeau amplification effect) as the cost of the formation of side products in lower and opposite enantioselectivity. Future studies of axial chirality using other arylating reagents are underway in our laboratories.

\section{Acknowledgements}

Financial support from the NSFC (21525208) and the SNNU is gratefully acknowledged.

Keywords: C-H activation $\bullet$ axial chirality $\bullet$ alkyne $\bullet$ arylation $\bullet$ desymmetrization

[1] a) T.-Z. Li, S.-J. Liu, W. Tan, F. Shi, Chem. Eur. J. 2020, 26, 15779; b) A. J. Metrano, S. J. Miller, Acc. Chem. Res. 2019, 52, 199; c) B. Zilate, A. Castrogiovanni, C. Sparr, ACS Catal. 2018, 8, 2981; d) Y.-B. Wang, B. Tan, Acc. Chem. Res. 2018, 51, 534; e) H. Yang, X. Yang, W. Tang, Tetrahedron 2016, 72, 6143; f) P. Loxq, E. Manoury, R. Poli, E. Deydier, A. Labande, Coord. Chem. Rev. 2016, 308, 131; g) D. Zhang, Q.-R. Wang, Coord. Chem. Rev. 2015, 286, 1; h) J. Wencel-Delord, A. Panossian, F. R. Leroux, F. Colobert, Chem. Soc. Rev. 2015, 44, 3418; i) E. Kumarasamy, R. Raghunathan, M. P. Sibi, J. Sivaguru, Chem. Rev. 2015, 115, 11239; j) G. Bringmann, D. Menche, Acc. Chem. Res. 2001, 34, 615.

[2] a) T. Yoshino, S. Satake, S. Matsunaga, Chem. Eur. J. 2020, 26, 7345; b) J. Loup, U. Dhawa, F. Pesciaioli, J. Wencel-Delord, L. Ackermann, Angew. Chem. Int. Ed. 2019, 58, 12803; c) J. Wencel-Delord, F. Colobert, Chem. Eur. J. 2013, 19, 14010; d) R. Giri, B.F. Shi, K. M. Engle, N. Maugel, J.-Q. Yu, Chem. Soc. Rev. 2009, 38, 3242.

[3] For selected reviews, see: a) T. G. Saint-Denis, R.-Y. Zhu, G. Chen, Q.-F. Wu, J.-Q. Yu, Science 2018, 359, eaao4798; b) G. Liao, T. Zhou, Q.-J. Yao, B.-F. Shi, Chem. Commun. 2019, 55, 8514; c) J. Pedroni, N. Cramer, Chem. Commun. 2015, 51, $17647 . \quad$ For individual reports, see: d); G. Liao, B. Li, H.-M. Chen, Q.-J. Yao, Y.-N. Xia, J. Luo, B.-F. Shi, Angew. Chem. Int. Ed. 2018, 57, 17151; e) G. Liao, Q.-J. Yao, Z.-Z. Zhang, Y.-J. Wu, D.-Y. Huang, B.-F. Shi, Angew. Chem. Int. Ed. 2018, 57, 3661; f) C. He, M. Hou, Z. Zhu, Z. Gu, ACS Catal. 2017, 7, 5316; g) S.-X. Li, Y.-N. Ma, S.-D. Yang, Org. Lett. 2017, 19, 1842; h) Q. Dherbassy, G. Schwertz, M. Chesse, C. K. Hazra, J. Wencel-Delord, F. Colobert, Chem. Eur. J. 2016, 22, 1735; i) D.-W. Gao, Q. Gu, S.-L. You, ACS Catal. 2014, 4, 2741; j) C. K. Hazra, Q. Dherbassy, J. Wencel-Delord, F. Colobert, Angew. Chem. Int. Ed. 2014, 53, 13871.

[4] a) B.-B. Zhan, L. Wang, J. Luo, X.-F. Lin, B.-F. Shi, Angew. Chem. Int. Ed. 2020, 59, 3568. b) Q. Wang, Z.-J. Cai, C.-X. Liu, Q. Gu, S.-L.You, J. Am. Chem. Soc. 2019, 141, 9504; c) G. Liao, H.-M. Chen, Y.-N. Xia, B. Li, Q.-J. Yao, B.-F. Shi, Angew. Chem. Int. Ed. 2019, 58, 11464; d) J. A. Carmona, V. Hornillos, P. Ramírez-López, A. Ros, J. Iglesias-Sigüenza, E. Gómez-Bengoa, R. Fernández, J. M. Lassaletta, J. Am. Chem. Soc. 2018, 140, 11067; e) X. Qiu, M. Wang, Y. Zhao, Z. Shi, Angew. Chem. Int. Ed. 2017, 56, 7233; f) J. Zheng, W.-J. Cui, C. Zheng, S.-L. You, J. Am. Chem. Soc. 2016, 138, 5242; g) Z.-J. Fang, S.-C. Zheng, Z. Guo, J.-Y. Guo, B. Tan, X.-Y. Liu, Angew. Chem. Int. Ed. 2015, 54, 9528; h) J. Zheng, S.-L. You, Angew. Chem. Int. Ed. 2014, 53, 13244; i) A. Ros, B. Estepa, P. Ramírez-Lopez, E.Álvarez,R. Fernandez, J. M. Lassaletta, J. Am. Chem. Soc. 2013, 135, 15730.

[5] F. Wang, Z. Qi, Y. Zhao, S. Zhai, G. Zheng, R. Mi, Z. Huang, X. Zhu, X. He, X. Li, Angew. Chem. Int. Ed. 2020, 59, 13288; X. Li, F. Wang, J. Jing, Y. Zhao, X. Zhu, X. Zhang, L. Zhao, P. Hu, W. Deng. Angew. Chem. Int. Ed. 10.1002/anie.202105093.

[6] K. Yamaguchi, J. Yamaguchi, A. Studer, K. Itami, Chem. Sci. 2012, 3, 2165.

[7] Q.-H. Nguyen, S.-M. Guo, T. Royal, O. Baudoin, N. Cramer, J. Am. Chem. Soc. 2020, 142, 2161.

[8] a) J. Mas-Roselló, A. G. Herraiz, B. Audic, A. Laverny, N. Cramer, Angew. Chem. Int. Ed. DOI: 10.1002/anie.202008166; b) Ł. Woźniak, J.-F. Tan, Q.-H. Nguyen, A. M. du Vigné, V. Smal, Y.-X. Cao, N. Cramer, Chem. Rev. 2020, 120, 10516; c) T. K. Achar, S. Maiti, S. Jana, D. Maiti, ACS Catal. 2020, 10, 13748; d) C. G. Newton, S.-G. Wang, C. C. Oliveira, N. Cramer, Chem. Rev. 2017, 117, 8908; e) B. Ye, N. Cramer, Acc. Chem. Res. 2015, 48, 1308.

[9] Z.-J. Jia, C. Merten, R. Gontla, C. G. Daniliuc, A. P. Antonchick, H. Waldmann, Angew. Chem. Int. Ed. 2017, 56, 2429.

[10] Y.-S. Jang, Ł. Woźniak, J. Pedroni, N. Cramer, Angew. Chem. Int. Ed. 2018, 57, 12901.

[11] M. Tian, D. Bai, G. Zheng, J. Chang, X. Li, J. Am. Chem. Soc. 2019, 141, 9527. 
[12] Q. Wang, W.-W. Zhang, H. Song, J. Wang, C. Zheng, Q. Gu, S.-L. You, J. Am. Chem. Soc. 2020, 142, 15678.

[13] H. Li, X. Yan, J. Zhang, W. Guo, J. Jiang, J. Wang, Angew. Chem., Int. Ed. 2019, 58, 6732.

[14] N. Umeda, H. Tsurugi, T. Satoh, M. Miura, Angew. Chem. Int. Ed. 2008, 47, 4019.

[15] a) Z. Qi, X. Li, Angew. Chem. Int. Ed. 2013, 52, 8995; b) R. Mi, G. Zheng, Z. Qi, X. Li, Angew. Chem. Int. Ed. $2019,58,17666$.

[16] a) Y.-C. Shi, R.-F. Yang, D.-W. Gao, S.-L. You, Beilstein J. Org. Chem. 2013, 9, 1891; b) T. Li, Z. Wang, C. Chen, B. Zhu, Adv. Synth. Catal. 2019, 361, 2855.

[17] a) B. Ye, N. Cramer, J. Am. Chem. Soc. 2013, 135, 636; b) B. Ye, N. Cramer, Angew. Chem. Int. Ed. 2014, 53, 7896.

[18] a) Z.-J. Du, J. Guan, G.-J. Wu, P. Xu, L.-X. Gao, F.-S. Han, J. Am. Chem. Soc. 2015, 137, 632; b) Y. Yang, R. Li, Y. Zhao, D. Zhao, Z. Shi, J. Am. Chem. Soc. 2016, 138, 8734; c) Y. Sun, N. Cramer, Angew. Chem. Int. Ed. 2017, 56, 364. For reviews, see: d) Y.-N. Ma, S.-X. Li, S.-D. Yang, Acc. Chem. Res. 2017, 50, 1480; e) J. Diesel, N. Cramer, ACS Catal. 2019, 9, 9164.

[19] Crystal data of CCDC 2006608 (product 3) and 2085200 (3') can be obtained free of charge from The Cambridge Crystallographic Data Centre. 